\title{
Gorlin syndrome associated with midline nasal dermoid cyst
}

\author{
E K Pivnick, A W Walter, M D Lawrence, M E Smith
}

\begin{abstract}
Gorlin syndrome is an autosomal dominant multisystem disorder characterised by multiple basal cell naevi, cysts of the jaw, pits of the palms and soles, skeletal anomalies, and various other defects. Patients with Gorlin syndrome have a predisposition to basal cell carcinomas and other neoplasms. This is the first report to describe the coexistence of Gorlin syndrome and a nasal dermoid cyst. A 4 year old girl was diagnosed with medulloblastoma and treated with surgery and radiation therapy. A genetic evaluation was sought because of the brain tumour, multiple small naevi localised mostly on the upper torso, and rib abnormalities. Biopsies of several naevi showed naevoid basal cell carcinoma. Past medical history was significant for a midline nasal punctum noted at birth. The significance of this finding was unrecognised until the dermoid cyst enlarged, just before the diagnosis of her brain tumour. A common tissue of origin exists between basal cell naevi, cysts of the jaw, and dermoid cysts. We propose that the association of these two rare conditions in one patient is not a chance occurrence.

(F Med Genet 1996;33:704-706)
\end{abstract}

Key words: Gorlin syndrome; nasal dermoid cyst.

Gorlin syndrome, also known as naevoid basal cell carcinoma syndrome (NBCCS), is a rare, dominantly inherited condition which is determined by a highly penetrant autosomal gene of variable expressivity. Sporadic cases have been described and are presumably a result of the high spontaneous mutation rate in the gene. The syndrome is characterised by the development of multiple naevoid basal cell carcinomas, cysts of the jaws, and pits of the palms and soles in the second decade of life or later. ${ }^{1}$

Affected subjects may also have skeletal anomalies, most commonly bifid ribs, macrocephaly, and hypertelorism. Various eye anomalies and ovarian fibromas are rarely described. This syndrome has been associated with an increased tendency to other neoplasms, especially medulloblastoma. ${ }^{2}$

We report a case of Gorlin syndrome associated with a midline nasal dermoid cyst. We propose that a nasal dermoid cyst is another pleiotropic manifestation of the gene responsible for NBCCS.

\section{Case report}

The proband, a female, was born at term by vaginal delivery after an uncomplicated pregnancy to a 24 year old primigravida and 25 year old father. Birth weight was $4224 \mathrm{~g}$. A midline punctum of the nasal tip was noted at birth.

Early gross motor development was somewhat delayed. The patient began walking at 19 months and rode a bicycle with training wheels at 4 years of age. At the age of 3 years the patient was noted to have numerous small pigmented naevi on the upper torso. A year later the nasal bridge became acutely swollen, a cyst was excised, and the pathology result showed a dermoid cyst. At the time of surgery a tract was found extending from the punctum to a cystic cavity underlying the nasal bridge. A few months later, the patient presented with acute severe headaches. Magnetic resonance imaging (MRI) of the head suggested a posterior fossa tumour (fig 1). A gross total resection was performed and the pathology was consistent with medulloblastoma. Curative therapy was provided using postoperative craniospinal radiation. Bone marrow and spinal fluid were negative for cancer.

The chromosomes from blood lymphocytes showed a normal 46,XX karyotype. The chest radiograph showed bifurcated ribs (fig 2). There was no evidence of cysts of the jaws or pits of the palms and soles.

A genetics evaluation was sought because of the brain tumour, multiple small naevi, and rib anomalies. On physical examination, the patient was large for her age (height $>95$ th centile, weight 90 th centile). She had macrocephaly, hypertelorism, and more than 30 dark raised naevi, mainly on the upper trunk, neck, and shoulders (fig 3). Several naevi were biopsied and all were found to be basal cell carcinoma (fig 4). The family history was

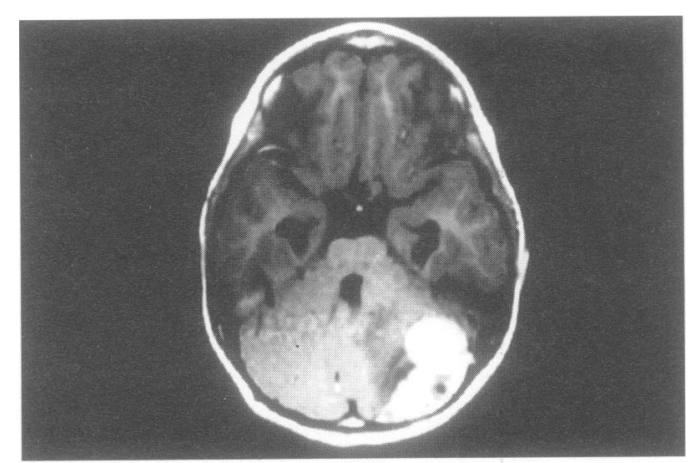

Figure 1 Brain MRI scan with contrast shows left cerebellar medulloblastoma. 

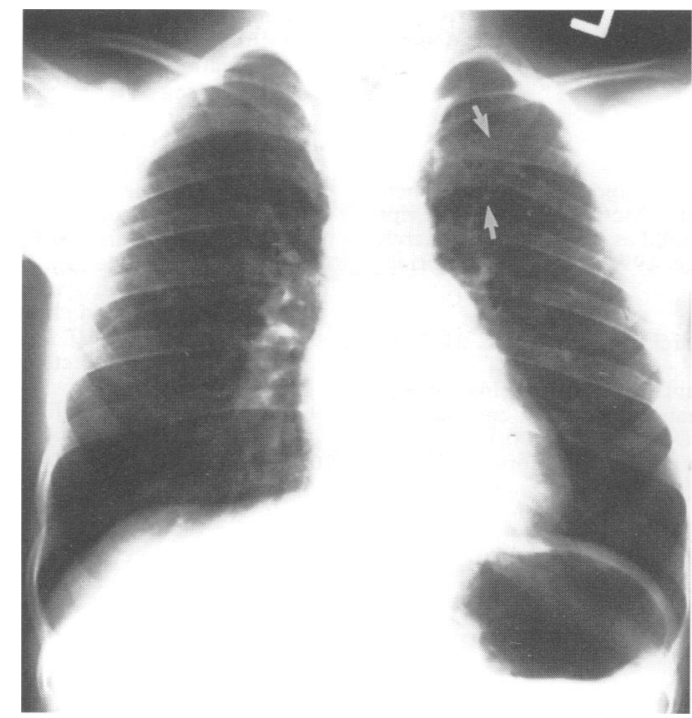

Figure $2 X$ ray of chest showing bifurcated rib on the left.

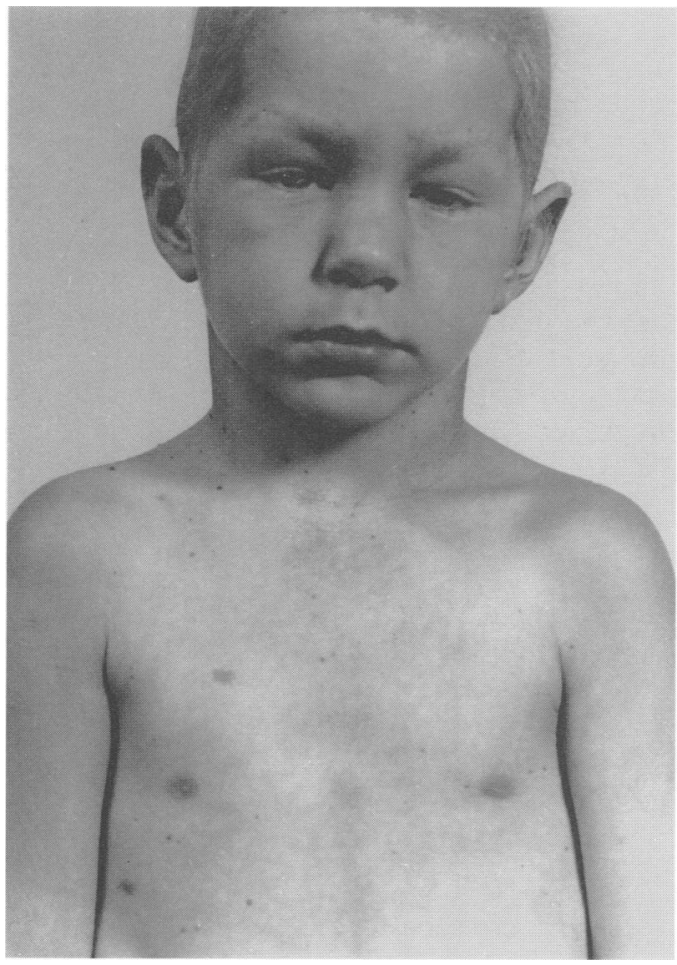

Figure 3 Photograph showing macrocephaly, hypertelorism, and scar on nasal bridge where dermoid cyst was excised. Note multiple naevi on the neck and upper trunk.

negative for Gorlin syndrome, cancer, tumours, or other abnormalities.

\section{Discussion}

Gorlin syndrome is an autosomal dominant disorder characterised by an increased predisposition to neoplasms as well as a wide variety of developmental defects. ${ }^{3}$ The manifestations of Gorlin syndrome are age dependent. In early childhood, the presence of multiple basal cell naevi, rib anomalies, and medulloblastoma suggest Gorlin syndrome, even in the absence of a family history. In the second and third decades of life, odontogenic keratocysts and dyskeratosis of the palms and soles are commonly associated with Gorlin syndrome. ${ }^{4}$ Many potential complications have been re-

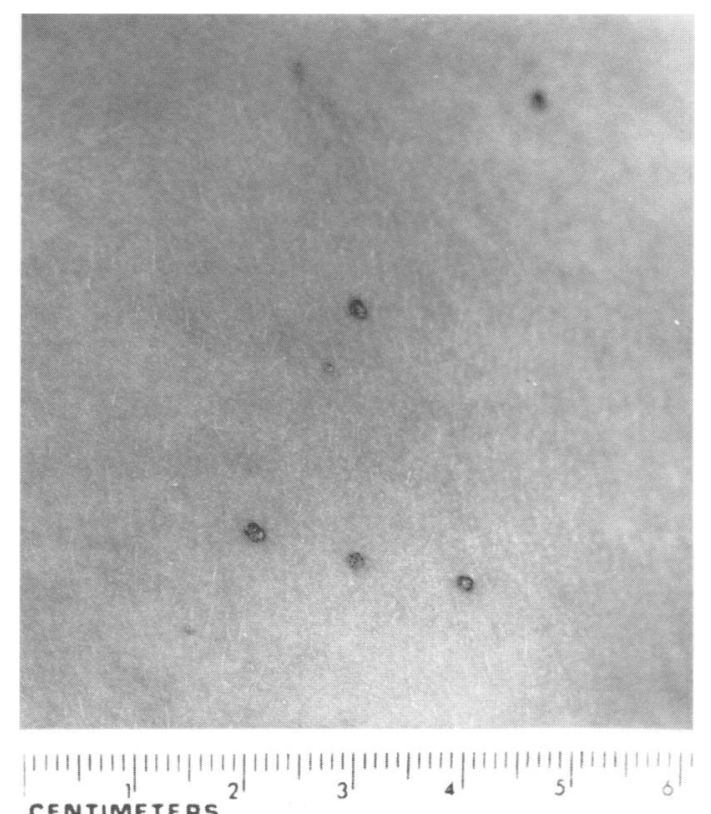

CENTIMETERS

Figure 4 Close up of the naevi proven to be basal cell carcinoma.

ported in connection with the naevoid basal cell carcinoma syndrome. Previously reported cases describe mesenteric cysts and subconjunctival epithelial cysts associated with this condition. ${ }^{56}$

The NBCCS gene had been mapped to chromosome $9 \mathrm{q} 22$ and probably functions as a tumour suppressor based on deletion of this region in many neoplasms related to the syndrome. ${ }^{7}$ A recently published report provides the first molecular evidence of a two hit mechanism for the pathogenesis of jaw cysts in patients with Gorlin syndrome. ${ }^{8}$ A similar mechanism might exist for dermoid cysts.

Dermoid cysts are congenital lesions most frequently found in the midline. It is thought that these lesions arise from the sequestration of midline ectodermal tissue. ${ }^{9}$ Nasal dermoids are rare and account for $8 \%$ of all dermoids in the head and neck region. Fifteen to $36 \%$ of patients with nasal dermoids have associated congenital anomalies. ${ }^{10}$

The occurrence of naevoid basal cell carcinoma syndrome and nasal dermoid cysts has not been described previously. This association is not unexpected since dermoid cysts have a common embryological tissue origin with odontogenic kerotocysts (jaw cysts) and dyskeratosis of the palms and soles (pits).

The finding of a cystic midline lesion should prompt an investigation for other associated congenital malformations or syndromes. We propose that NBCCS should be considered as well.

\section{Note added in proof}

An evolutionarily conserved human sequence (PTC) was recently identified as a candidate gene for NBCCS. (Hahn $\mathrm{H}$, Wicking $\mathrm{C}$, Zaphiropoulos G, et al. Mutations of the 
human homolog of Drosophila patched in the nevoid basal cell carcinoma syndrome. Cell 1996;85:841-51).

We are greatly indebted to the patient and her family for their cooperation. We also thank Kathy McCalla for manuscrip preparation. This paper was presented as a poster at the March of Dimes 25th Clinical Conference, 1994, in Orlando, Florida.

1 Gorlin RJ. Nevoid basal cell carcinoma syndrome. Medicine 1987;66:99-113.

2 Lacombe D, Chateil JF, Fontan D, et al. Medulloblastoma in the nevoid basal-cell corcinoma and review of the litercinoma syndrome: case reports

3 Gorlin RJ. Nevoid basal cell carcinoma syndrome. Dermatol Clin 1995;13:113-25.
4 Evans DGR, Ladusans EJ, Rimmer S, et al. Complications of the nevoid basal cell carcinoma syndrome: results of a of the nevoid basal cell carcinoma syndrome: results

5 Clendenning WE, Herdt JR, Block JB. Ovarian fibromas and mesenteric cysts: their association with hereditary basal cell cancer of the skin. Am $\mathcal{f}$ Obstet Gynecol 1963;87:1008-12.

6 Levine DJ, Robertson DB, Varma VA. Familial subconjunctival epithelial cysts associated with the nevoid basal cell carcinoma syndrome. Arch Dermatol 1987;123:23-4.

7 Gailani MR, Bale SJ, Deffell DJ, et al. Developmental defects in Gorlin syndrome related to a putative tumor suppressor gene on chromosome 9. Cell 1992;69:111-17.

8 Levanat S, Gorlin RJ, Fallett S, et al. A two-hit model for developmental defects in Gorlin syndrome. Nature Genet 1996;12:85-7.

9 James P, Worthington JP, Sinclair JH. Median dermoid cyst. NZ Dental $f$ 1991;88:17-19.

10 Taylor BW, Erich JB. Dermoid cysts of the nose. Mayo Clin Proc 1967;42:488-94. 